\title{
A Novel Aided System Based on RBR for Unsafety Event Interpretation of Civil Aviation
}

\author{
Yang Jiao ${ }^{1, a^{*}}$, Huabo Sun ${ }^{1, b}$, Chun Wang ${ }^{1, c}$ and Jingru Han ${ }^{1, d}$ \\ ${ }^{1}$ China Academy of Civil Aviation Science and Technology, \\ Civil Aviation Safety Analysis and Prevention Engineering Technology Center, \\ Beijing 100028, China \\ ajiaoyang@castc.org.cn, bsunhb@castc.org.cn, \\ cwangchun@castc.org.cn, ${ }^{\mathrm{d}}$ hanjr@castc.org.cn \\ * The Corresponding author
}

Keywords: AGS; Civil Aviation; Unsafety Event; RBR

\begin{abstract}
According to the problem of invalid unsafety events in Flight Operational Quality Assurance (FOQA), an aided interpretation scheme based on Rule-Based Reasoning (RBR) is proposed. On the base of analysis of invalid unsafety events triggered by Advanced Ground Station (AGS), Unsafety Event Aided Interpretation system is developed. With ETL tool, the system completes the synchronization of AGS flight data with initial event library. By constructing rule database, RBR mechanism is introduced. Finally the system shows the results of the analysis adopting java web technology. In practical application, the system runs stably and analysis results are directly. To a certain extent, the system realizes automatic verification of authenticity and improves the efficiency of artificial interpretation. It provides technical support for improving the safety management level of Civil Aviation.
\end{abstract}

\section{Introduction}

As the economic development in China, travelling by airplane becomes normal. Civil aviation industry develops rapidly. Now, at least 3000 aircrafts have been in service. The average flights are more than 13,000 times in each day. As the numbers growing, ensuring flight safety becomes more important. China has carried out a series of work in the field of civil aviation security. Flight operational quality monitoring(FOQA) is one of the most important methods to ensure flight safety in the world, which has gotten approve generally in Civil Aviation. CAAC has implemented FOQA in all certification holders since 1997 and issued airworthiness directives. It is stipulated that a quick access recorder (QAR) or equivalent equipment shall be installed in the transport aircraft which is registered and operated in China from January 1, 1998.

AGS is an analysis system which is developed by Safran Electronics \& Defense corp. This system analyzes flight conditions and decodes flight parameter for various types of aircraft. AGS can read binary data from the QAR device and decode to the corresponding engineering values. Also, AGS can trigger and save unsafe event according to program settings. However, the triggered events contain a large proportion of invalid events, which need to be filtered by human interpretation. Artificial interpretation increases the workload. At the same time, valid events may also be filtered by mistake. Therefore, it is necessary to be staffed with specially trained analysis personnel in order to ensure the accuracy of interpretation.

To solve the above problems, this research takes a large number of unsafe events and flight data and extracts typical invalid events as sample. On this basis, the rule database is constructed and the aided interpretation system is implemented by combining Rule-Based Reasoning (RBR). RBR refers to the formal description of expert knowledge in related fields, forming systematic rules, and has strong deductive reasoning ability. At present, the rule reasoning mechanism has been widely applied to intelligent systems. This system introduces the RBR into the unsafe events interpretation of civil aviation. It provides reasoning function and preliminary identifies the authenticity of the 
incident. Also it outputs the analysis report as reference for later interpretation. Aided Interpretation System enhances the diagnosis level of unsafety events and reduces the workload. This is of great significance to the development of Civil Aviation.

\section{Design of the System.}

\section{Overall Function Design of the System.}

This system can accomplish the following functions:

1) Data synchronization: Through ETL tool, system synchronize AGS data(unsafety event and flight data ) to local database. These data, as the original data of the system, provide data support for rule reasoning in the late.

2) Maintenance of rule library: Rule reasoning needs the support of data from rule library. With the widely using and development of system, the rule library will be constantly improved. Through the system maintenance function, operator can add, delete and modify the rule library.

3) Aided interpretation: Aided Interpretation is the core function of the system。 It refers to the use of rule reasoning mechanism to analyze the original unsafe events intelligently。 The results of aided interpretation can be used as the basis for manual interpretation in the late.

4) System maintenance: Basic information maintenance of system, such as personnel, permissions and other information maintenance.

\section{Structure of the System}

The Aided Interpretation System consists of two major subsystems, information maintenance subsystem and event reasoning subsystem。The former is mainly responsible for the maintenance of system information and database information, as well as information display。 The latter is mainly background reasoning operation and reasoning about events according to the rules. The system structure is shown in Fig. 1:

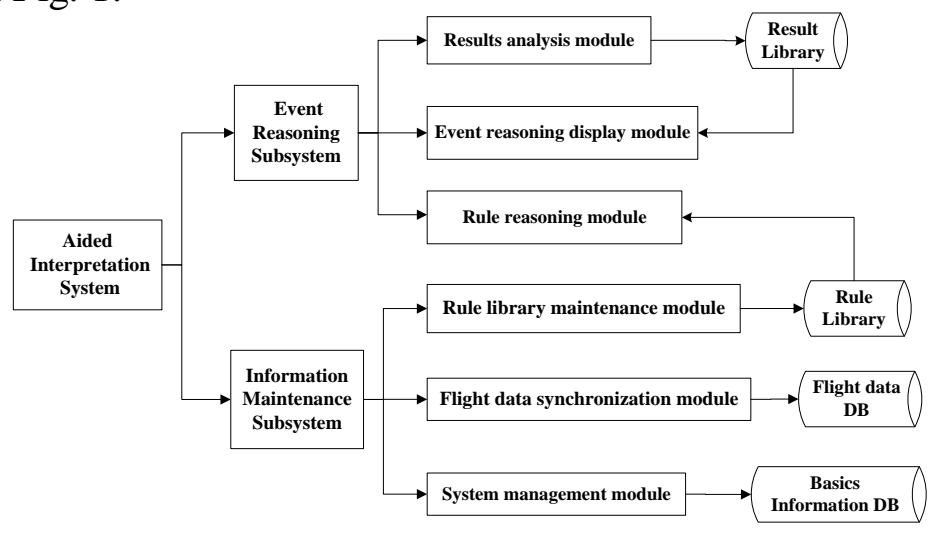

Figure 1. Finite Structure diagram of the system

The flight data synchronization module uses the ETL tool to extract flight data from the AGS database once a day, including the event data that is triggered by AGS and the engineering value data generated after QAR decoding. The rule library maintenance module is responsible for the establishment of reasoning rules, and describes the specific structure of the following chapters. The reasoning design table structure will be presented in the later section。 The rule reasoning module which runs operation in the background is responsible for reasoning the authenticity of events. The results analysis module and reasoning display module provide the displaying the reasoning results.

\section{Workflow of the System}

The system mainly contains three work flow, data synchronization, system maintenance process and event reasoning process. As shown in Fig. 2. 


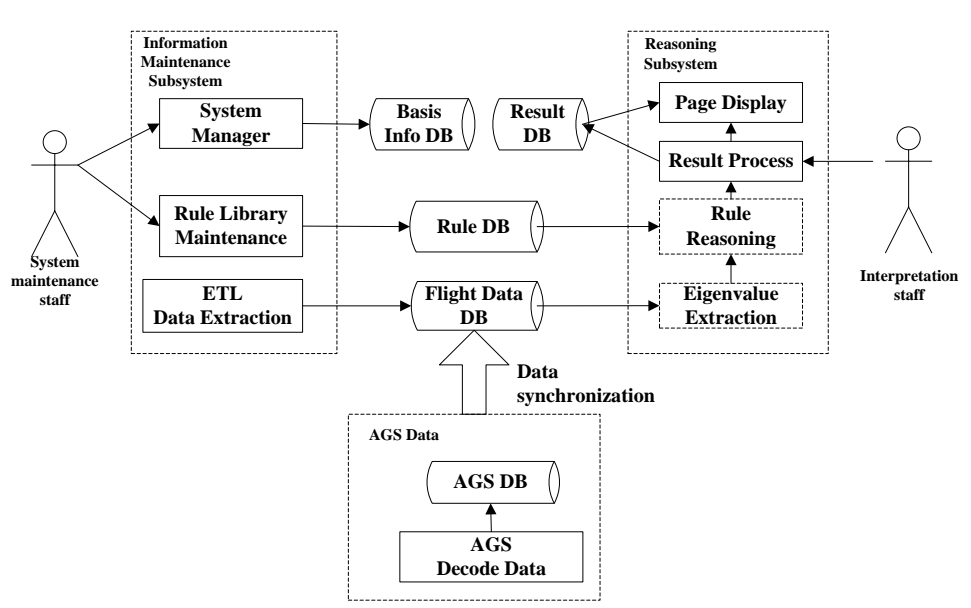

Figure 2. Finite Workflow diagram of the system

Data synchronization triggered at 24 o'clock every night in order to synchronize flight data and events generated by AGS in the previous day. System maintenance process refers to the maintenance of system basic information and rule library information. Event reasoning process refers to the validity of reasoning about existing events according to the rule library.

\section{Event Reasoning Process}

The event reasoning process is shown in Fig. 3: the staff who deals with interpretation data triggers the rule reasoning function, By loop matching, the system performs the judgement of the events' authenticity according to the current rule library, and gives the reasoning analysis result. After reasoning, events are divided into three states: invalid, review and valid. After consulting the results report, the staff analyzes the original flight data pertinently and decides the authenticity of events. If the nature of event by reasoning is valid, but the nature by manual decision is invalid, then the system maintainer can abstract the decision rule and add it to the system rule base. Similarly, if the nature of event by reasoning is invalid, but finally the event defined as a valid event, this shows that the existing rules are not strict enough to modify the rule library.

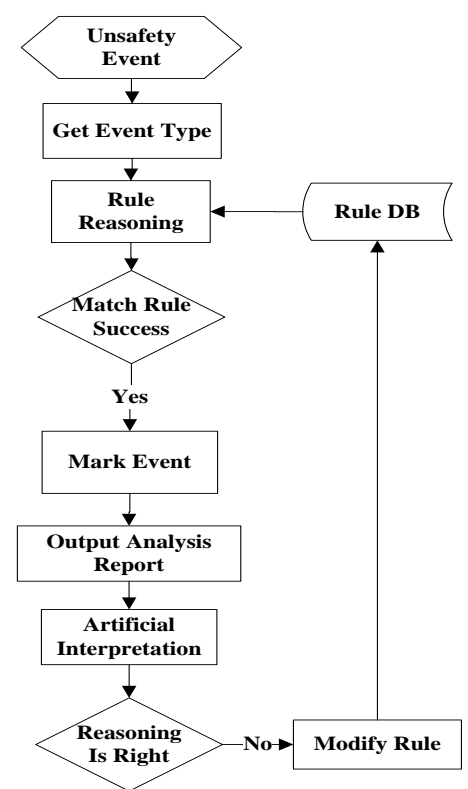

Figure 3. Finite Event reasoning flow diagram

\section{Design of RBR Model}

Rule Representation. The system uses production representation to describe rules. At present, production representation has been widely used in intelligent analysis systems. For example, the 
reference [7] is on the field of rail transit emergency assistance, reference [8] is on the field of coal industry fault diagnosis. The basic form of production is $\mathrm{P} \rightarrow \mathrm{Q}$ or IF $\mathrm{P}$ THEN Q. $\mathrm{P}$ is the premise of production, also known as the antecedent, which gives the prerequisite for the use of the production form and consists of a logical combination of facts。Q is a set of conclusions or operations, also known as the production post, which indicates the conclusions or actions that should be carried out when the current $\mathrm{P}$ is satisfied. On this basis, we improve the rule representation, which is upgraded from single premise to premise combination (the intersection or union of multiple premises). That means if the premise P1 or (and) P2 are satisfied, then the conclusion Q can be drawn.

Rule Storage. According to the combination rule representation method, this system does not have a simple one to one table structure, but splits rule's table into three tables: attribute table, rule table and event rules table. Table structures are shown in Table 1, Table 2, Table 3:

Table 1 Rule attribute table

\begin{tabular}{|l|l|l|l|}
\hline $\begin{array}{l}\text { Attribute } \\
\text { No. }\end{array}$ & $\begin{array}{l}\text { Attribute } \\
\text { Name }\end{array}$ & $\begin{array}{l}\text { Eigenval } \\
\text { ue }\end{array}$ & $\begin{array}{l}\text { Confiden } \\
\text { ce Level }\end{array}$ \\
\hline ATTR1 & NAME1 & V1 & CF1 \\
\hline ATTR2 & NAME2 & V2 & CF2 \\
\hline ATTR3 & NAME3 & V3 & CF3 \\
\hline
\end{tabular}

Table 2 Rule table

\begin{tabular}{|l|l|l|l|}
\hline Rule No. & Premise & Conclusion & $\begin{array}{l}\text { Confiden } \\
\text { ce Level }\end{array}$ \\
\hline RULE1 & $\begin{array}{l}\text { ATTR1+AT } \\
\text { TR2 }\end{array}$ & RSL1 & CF3 \\
\hline RULE2 & $\begin{array}{l}\text { ATTR1*AT } \\
\text { TR2 }\end{array}$ & RSL2 & CF4 \\
\hline RULE3 & $\begin{array}{l}\text { ATTR2*AT } \\
\text { TR3 }\end{array}$ & RSL3 & CF5 \\
\hline
\end{tabular}

Table 3 Relationship between event and rule

\begin{tabular}{|l|l|}
\hline Event No. & Rule No. \\
\hline EVENT1 & RULE1 \\
\hline EVENT1 & RULE2 \\
\hline EVENT2 & RULE1 \\
\hline
\end{tabular}

The rule property table stores all rules' attributes. The rule table stores a relationship of rule attributes. When the system cannot find the appropriate combination of rules, it determines that the event is valid. At present, there is only intersection relation between the combinations of multiple conditions in the system. If $P$ is a union of multiple conditions, such as $P=P_{1} \cap P_{2} \cdots P_{n}$, then the confidence is calculated as follows:

$$
\mathrm{CF}(\mathrm{P}, \mathrm{Q})=1-\mathrm{CF}\left(P_{1}, \mathrm{Q}\right) \times \mathrm{CF}\left(P_{2}, \mathrm{Q}\right) \cdots \times \mathrm{CF}\left(P_{n}, \mathrm{Q}\right)
$$

The third table is designed to improve the retrieval efficiency of the rules. At present, there are dozens of unsafety events in the field of civil aviation, and the triggering conditions of each event are different, so the reasoning rules are different. In the reasoning process, irrelevant rules can be filtered depending on the type of event. By means of a large amount of previous data, there are many-to-many relationship between event types and rules. This means that an event can have 
multiple rules, and a rule can be applied to many events.

Rule Reasoning. The rule reasoning process is shown in Fig. 4. Depending on the event type, get the relevant rules, loop to match. As long as the rule is matched and the confidence level is 1 , then the rule is determined as a necessary and sufficient condition. The system no longer continues to match the other rules, but identifies as invalid event directly. If the match ended, but the confidence is still 0 , that means there is no match to the relevant rules. The result is the event is valid. The third case is although there is a matching rule, but the confidence is less than 1 . In this case, the system calibrates the event status to be review.

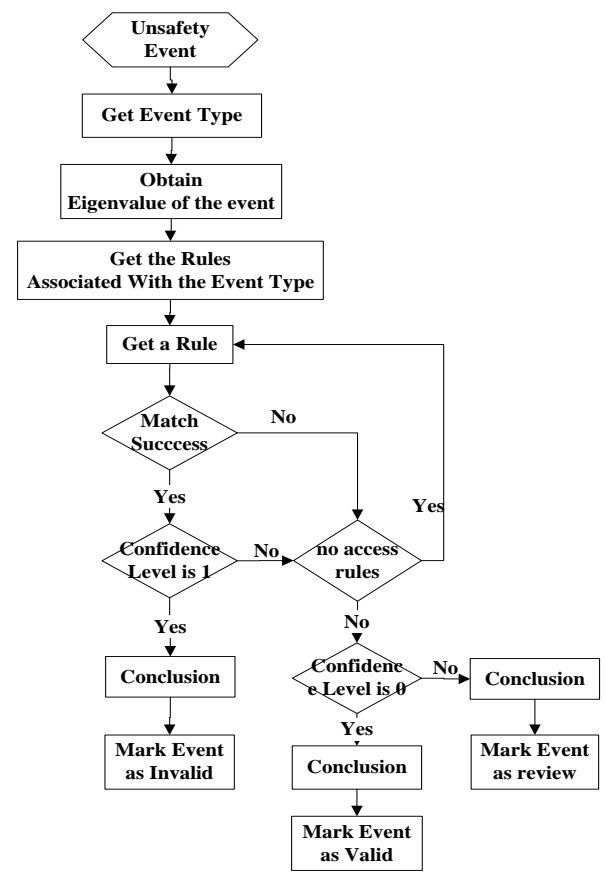

Figure 4. Finite Rule reasoning flow diagram

\section{Application Example}

The following describes the reasoning process based on a case. The paper chooses the event which is triggered by tail strike during the flight phase of lift off. At present, the relevant analysis department mainly uses the pitch angle, which sampled on the moment of lift off the ground, to determine whether to wipe the tail. When the pitch angle is greater than the reference angle, the unsafety event of tail strike is triggered. However, by looking at the AGS event library, it was discovered that a number of invalid tail strike events were triggered during the decoding analysis. Based on these samples, we extract feature attributes, as shown in Table 4.

Table 4 Tail strike event attribute

\begin{tabular}{|l|l|l|l|}
\hline $\begin{array}{l}\text { Attribute } \\
\text { No. }\end{array}$ & $\begin{array}{l}\text { Attribute } \\
\text { Name }\end{array}$ & Eigenvalue & $\begin{array}{l}\text { Confidence } \\
\text { Level }\end{array}$ \\
\hline 1 & PITCH & $<10 \mathrm{deg}$ & 1.00 \\
\hline 2 & IAS & $>140 \mathrm{knot}$ & 0.30 \\
\hline 3 & RATL & $>5 \mathrm{feet}$ & 0.50 \\
\hline 4 & PITCH_RATE & $<5.5 \mathrm{deg} / \mathrm{s}$ & 0.50 \\
\hline 5 & AC_TYPE & 0 & 1.00 \\
\hline
\end{tabular}

In table 4, AC_TYPE is aircraft type, IAS is airspeed, RATL is radio altitude, and PITCH_RATE represents aircraft pitch rate. Set the relevant rules as follows:

Rule1: IF PITCH < 10,Then pitch angle error, confidence level sets 1.00. 
Rule2: IF AC_TYPE $=0$ AND PITCH $<10$, Then aircraft type error, confidence level sets 1.00 .

Rule3: IF RATL > 5 AND IAS > 150, Then both speed and height are sufficient at lift off ground moment, confidence level sets 0.85 .

Rule4: IF IAS $>30$ AND PITCH_RATE $<6$, Then airspeed and pitch rate change coordination, confidence level sets 0.85 .

According to the above representation, the rule table is constructed, as shown in Table 5.

Table 5 Tail strike Event Rule

\begin{tabular}{|l|l|l|l|}
\hline $\begin{array}{l}\text { Rule } \\
\text { No. }\end{array}$ & $\begin{array}{l}\text { Premis } \\
\text { e }\end{array}$ & Conclusion & $\begin{array}{l}\text { Confiden } \\
\text { ce Level }\end{array}$ \\
\hline RULE1 & 0001 & Pitch angle is normal & 1.00 \\
\hline RULE2 & $\begin{array}{l}0005^{*} 0 \\
001\end{array}$ & Aircraft type is error & 1.00 \\
\hline RULE2 & $\begin{array}{l}0002 * 0 \\
003\end{array}$ & $\begin{array}{l}\text { Both airspeed and height are } \\
\text { sufficient } \\
\text { at lift off ground moment }\end{array}$ & 0.85 \\
\hline RULE2 & $\begin{array}{l}0003^{*} 0 \\
004\end{array}$ & $\begin{array}{l}\text { Airspeed and pitch rate change } \\
\text { coordination }\end{array}$ & 0.85 \\
\hline
\end{tabular}

The system reasoning page is shown in Fig. 5. The list of events is displayed in the figure, including event date, event number, event description, aircraft number, flight phase, event status, confidence level, and reasoning result. Click one of the reasoning results to eject a detailed reasoning report of the event, as shown in Fig. 6. In the report, the aircraft type is Airbus 320, with airspeed of 140 knots and pitch angle of 13 degrees, which is not exceeding the limit of 13.5 degrees, but the AGS triggered the event. The reason of artificial interpretation is that the aircraft type parameter is empty, which causes the pitch angle limit value of this aircraft is empty. Finally this event is triggered. According to the rule reasoning, the RULE2 premise is matched. Therefore the system draws the conclusion that the aircraft type is error and the event is marked as invalid state. This analysis result coincides with the actual situation.

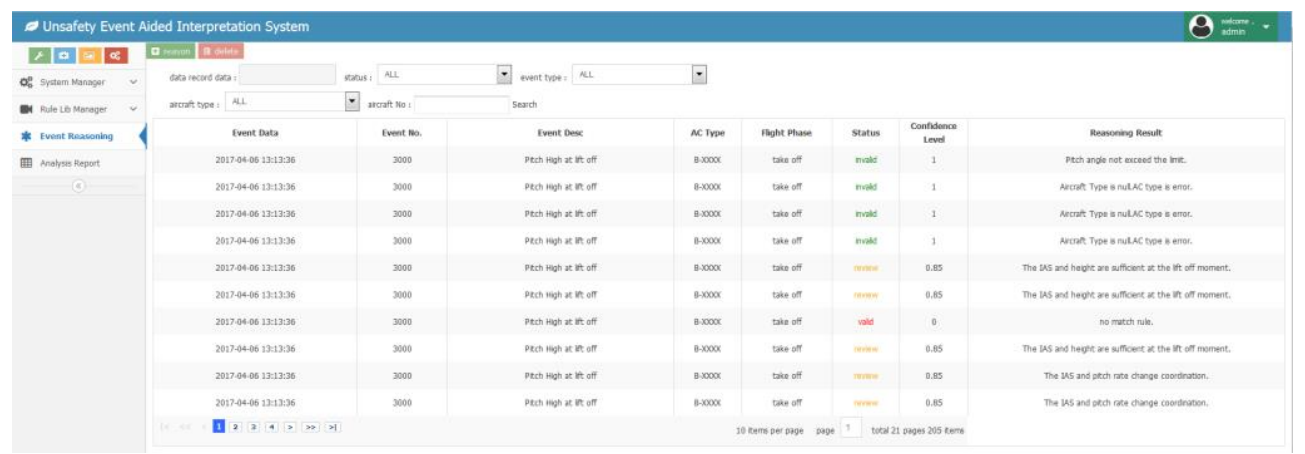

Figure 5. Finite System reasoning list page

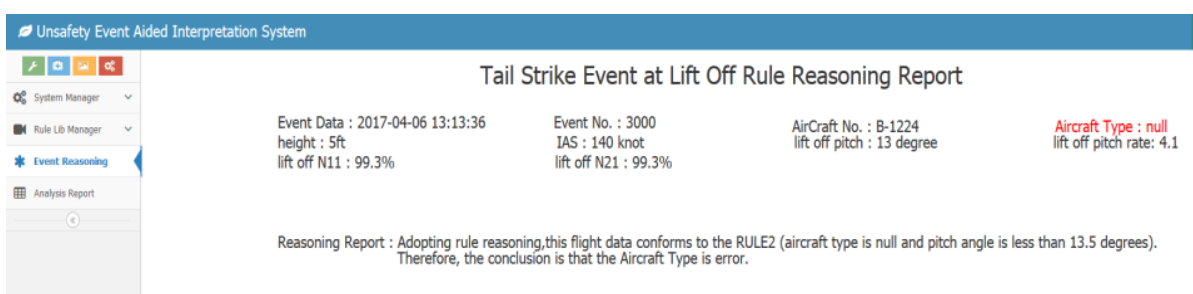

Figure 6. Finite Reasoning detail report page 


\section{Conclusion}

In this paper, an aided system based on RBR for unsafety events is designed and implemented. The system introduces rule reasoning into the field of civil aviation to analyze unsafe event. A rule representation method for civil aviation unsafe event is proposed, and a rule database is constructed. Then combining the characteristics of civil aviation unsafe event, the reasoning process is described. In application, the system can give the reasoning result about the event authenticity which provides data support for artificial interpretation and improves the efficiency of event interpretation. In a word, the research conforms to the development policy of informatization, intelligence and timeliness in the field of civil aviation safety.

\section{Acknowledgment}

The work presented in this paper is supported by Natural Science Foundation of China (ID: U1533102) and civil aviation safety project (ID: DFS20150125).

\section{References}

[1] YU Liling. Review and Prospect of Civil Aviation Flight Quality Monitoring in China [J]. aviation safety, 2012,8(140): 51-53.

[2] Advisory Notice. Flight Quality Monitoring (FOQA) Implementation and Management [R]. AC-121/135-FS-2012-45.

[3] Information on http://baike.baidu.com

[4] Sun Ruishan, YANG yixuan. Risk Prediction of Aircraft Tail Strike Events during Take-off Phas. Safety and Environmental Engineering,2016,23(2):153-156.

[5] SHUN Ping, LI FUHai. Accident analysis and prevention measures of the end of the takeoff stage [J]. International Aviation, 2008(11):40-42.

[6] LUO Qin, YANG Yong-tai, MO Yi-hong. Design and Realization of Emergency Auxiliary Decision-Making System of Traffic Control for Urban Rail Transit [J]. RAILWAY TRANSPORT AND ECONOMY,2017,39(2):85-89.

[7] JIANG Z N, WANG H, WEI Z Q. Faults diagnosis Expert system based on case reasoning and rule reasoning[J]. Computer Engineering, 2011, 37 (1): 238-243.s.

[8] Smith A, Cassell R, Yang YE, et al. Feasibility demonstration of an aircraft performance risk assessment model[C]//Proceedings of 19th Digital Avionics Systems Conference. Piscataway, NJ:IEEE/AIAA,2000,1:4.D.4-1 - 4.D.4-8.

[9] Romanenko L G. Samarova G G. Aircraft longitudinal control without a pitch command in the autopilot[J]. Russian Aeronautics, 2014, 57(4):361-367.

[10]LI Cong,WANG Yong,TANG Chuanlin. An Autonomous Tactical Decision Making for Unmanned Aerial Vehicles Based on CBR and RBR [J].Journal of Air Force Engineering University(NATURAL SCIENCE EDITION),2017,18(1):13-19.

[11] XU Y B, WANG T. Research on Emergency Deci-sion Method of Unconventional Emergency in Subway Based on Case-based Reasoning[J]. Journal of Safety Science and Technology, 2013, 9 (8): 35-40.

[12] YUAN X F, LI H X. Case-Based Reasoning Energency Decision Method of Gas Accident in Coal Mines [J]. Journal of Liaonin-g Technical University (Natural Science), 2012, 31(5): 28-33.

[13] Wiegmann D A, Shappell S A. A human error analysis of commercial aviation accidents using the human factors analysis and classification system[R].DOT /FAA/AM-01/3,2001.

[14] LANG Ronglin,PAN Lei,Lu Yongle.Fault Diagnosis Expert System Based on Flight Data for Civil Aviation[M].National Defence Industry Press,2014.2. 